\title{
A novel streptomycin and spectinomycin resistance Gene cassette occurence in $E$. cloacae isolated from Zhenjiang
}

\author{
Hongxia Wu \\ Department of Microbiology, Jiangyin people's hospital, Jiangyin, China, 214400
}

\section{Email address:}

jywuhongxia@126.com

\section{To cite this article:}

Hongxia Wu. A Novel Streptomycin and Spectinomycin Resistance Gene Cassette Occurence in E. cloacae isolated from Zhenjiang. Clinical Medicine Research. Vol. 3, No. 5, 2014, pp. 142-144. doi: 10.11648/j.cmr.20140305.16

\begin{abstract}
The aadA genes, encoding resistance to streptomycin and spectinomycin, have been found as gene cassettes in different gram-negative and gram-positive bacterial species. The present report has revealed that the sequence of a new gene, aadA5, combining with the trimethoprim resistance gene dfr 17 occured in a class 1integron. The integron was identified in a nosocomial pathogen Enterobacter cloacae isolates, which indicated that integrons are specialized genetic elements that were capable of capturing, integrating and mobilizing gene-cassette by site-specific recombination and integron was a dangerous factor to lead to bacterial resistance.
\end{abstract}

Keywords: E. Cloacae, Class 1 Integron, Resistance

In recent years, Enterobacter cloacae (E. cloacae) has become a well-recognized nosocomial pathogen. E. cloacae isolates from clinical specimens may be resistant to multiple antibiotics. For example, E. cloacae is intrinsically resistant to ampicillin and narrow-spectrum cephalosporins [1]. And a substantial proportion of multiresistant E. cloacae isolates carry integrons. Integrons are specialized genetic elements that was capable of capturing, integrating and mobilizing gene cassettes by site-specific recombination. Gene cassettes mainly encoded antibiotics genes. There are five classes integrons involved in bacterial resistance to date, While class 1 integrons are most frequently found in antibiotic-resistant gram negative bacteria [2]. The structure of the class 1 integron includes 5' and 3' conserved segments and a variable region [3].

The aadA genes which were first repoted by Hollingshead and Vapnek [4], are the only characterized genes that encode both streptomycin and spectinomycin resistance, and many of these genes are found as gene cassettes in class 1 integron [5]. The present report characterizes the nucleotide sequence and expression of a novel streptomycin and spectinomycin resistance gene located as a gene cassette. In a two-year period ( 2005-2006 ), 15 multiresistant E. cloacae strains were isolated in our laboratory, which carried a aadA5-containing integron. To the best of our knowledge, E. cloacae strains carrying aminoglycoside-3'-adenylyltransferase genes have not been reported before. Therefore, we undertook this study to analyse the structure of the aadA5-containing integron.

\section{Materials and Methods}

\subsection{Bacterial Strains and Susceptibility Testing}

The E. cloacae isolates were identified by the conventional method, and with the VITEK system card (bioMérieux, Hazelwood, MO, USA). Antibiotic-containing discs ( Oxoid Ltd., England ) were used for routine antibiograms by disc diffusion assay. MICs of antimicrobial agents were determined by agar dilution in a Mueller-Hinton Media (Oxoid Ltd., Basingstoke, Hampshire, England ) according to the guidelines of the NCCLS [6]. Escherichia coli ATCC 25922 was used as MIC reference strain.

\subsection{E. Cloacae DNA Extraction}

The E. cloacae DNA was extracted using the boiling lysated method [7]. The template was prepared by suspending a loopful of each isolate in $200 \mathrm{~mL}$ of sterile water, followed by boiling for $10 \mathrm{~min}$ and centrifuging for $3 \mathrm{~min}$.

\subsection{Amplification and Sequencing of Class 1 Integrons}

The gene cassette regions for the class 1 integrons were performed by PCR amplification with the following sets of primers: for the class 1 integron, 5'CS-F (5'-GGC ATC 
CAA GCA GCA AG-3') and 3'CS-R (5'-AAG CAG ACT TGA CCT GAT-3') (8). PCRs were performed in volumes of $15 \mu \mathrm{l}$ under the following conditions: $1.5 \mu 1 \quad 10 \times \mathrm{PCR}$ Buffer $\left(\mathrm{Mg}_{2}{ }^{+}\right.$plus), $0.2 \mathrm{mM}$ of each deoxynucleoside triphosphate, $0.1 \mu \mathrm{M}$ of each primer, and 1.5 units of Taq DNA or LA Taq DNA polymerase (Takara Biotechnology (Dalian) Co., Ltd.). for $10 \mathrm{~min}$ at $94^{\circ} \mathrm{C} ; 35$ cycles, with 1 cycle consisting of 45 seconds at $94^{\circ} \mathrm{C}, 1$ to $2 \mathrm{~min}$ at 55 to $60^{\circ} \mathrm{C}$, and 1 to $2 \mathrm{~min}$ at $72^{\circ} \mathrm{C}$, and a final step of $10 \mathrm{~min}$ at $72^{\circ} \mathrm{C}$. Sequencing reactions were performed by Shanghai GeneCore BioTechnologies Co.,Ltd. Database similarity searches for nucleotide and deduced amino acid sequences were carried out at the NCBI website (http://www.ncbi.nlm.nih.gov).

\subsection{Nucleotide Sequence Accession Number}

The nucleotide sequences of the aadA5 gene of E. cloacae isolate have been assigned to the GenBank nucleotide sequence database (GenBank accession no EF571855).

\section{Results and Discussion}

\subsection{Properties of 15 E. Cloacae Strains}

MIC testing revealed that E. cloacae isolates was resistant to most $\beta$-lactams, including ampicillin, ampicillin-sulbactam, piperacillin, piperacillin-tazobactam, cefalothin, cefoxitin, cefotaxime, ceftazidime, aztreonam, and E. cloacae isolates was high-level resistant to streptomycin and spectinomycin. MICs of aztreonam for the isolate was 64 $\mathrm{mg} / \mathrm{L}$. MICs of ampicillin, ampicillin-sulbactam, piperacillin, piperacillin-tazobactam, cefalothin, cefoxitin, cefotaxime and ceftazidime were $>128 \mathrm{mg} / \mathrm{L}$.

\subsection{Sequence Analysis of the aadA5-Containing Integron}

$$
\text { 5'-conserved segment } \quad 3 \text { '-conserved segment }
$$

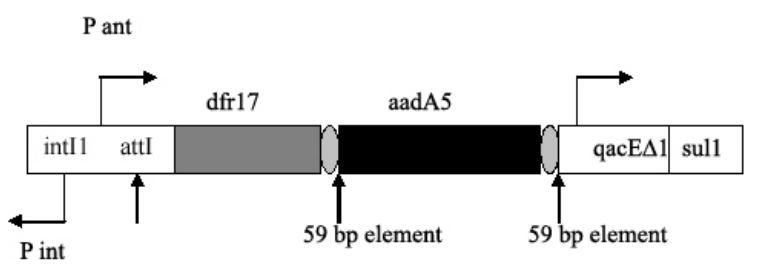

Fig 1. Schematic map of the novel class 1 integron containing the aadA5 gene cassette from the E. cloacae isolate. Designations are as follows: intI1, integrase; attI, recombination site; $d$ fr17, dihydrofolate reductase (trimethoprim resistance) gene; aadA5, streptomycin and spectinomycin resistance gene; qacE $\Delta 1$, quaternary ammonium compound resistance gene; sull.

PCR-based experiments showed that the aadA5 gene occurred 15 multiresistant E. cloacae strains and also found the 15 isolates had the identical amplicon. Sequence analysis of the $1664 \mathrm{bp}$ amplicon revealed the structure of the class 1 integron, such as the $5^{\prime}$-CS element containing an IntI1 integrase gene with its own promotor region and the $3^{\prime}-\mathrm{CS}$ element containing qacE $\Delta 1$. The integron contained insert gene cassettes dfr17, aadA5, and two putative 59 base element. The aadA5 gene was located immediately downstream of the first putative 59 base element. The aadA5 gene cassettes had a 59 bp element, and the qacE $\Delta 1$ gene also had a core site (Fig. 1).

The aminoglycoside-3'-adenylyltransferase genes have spread among gram-negative bacilli, including Pseudomonas aeruginosa, Acinetobacter baumannii and Escherichia coli $[8,9]$. However, this enzyme was rarely found in E. cloacae. The presence of the mobile aadA5 gene cassette integron in E. cloacae suggests that the resistance can spread to other members of the family Enterobacteriaceae [10-12]. In the new class 1 integron in this study also contained a dihydrofolate reductase gene (dfr17) besides aadA5 cassette, suggesting that the gene responsible for the trimethoprim resistance.

The present study has characterized a novel streptomycin and spectinomycin resistance gene cassette found in a class 1 integron. The distribution of this gene is still to be investigated. The novel gene cassette is present in a class 1 integron, which is mobile. These factors enhance the mobiling possibilities for the aadA5 gene, and the conditions of transfer and the molecular epidemiology of this gene cassette will need further attention in the future.

\section{Conclusion}

The present work indicated that integrons are specialized genetic elements that were capable of capturing, integrating and mobilizing gene-cassette by site-specific recombination and integron was a dangerous factor to lead to bacterial resistance.

\section{Acknowledgments}

This work was supported by the Founfation of Social Development of Jiangsu Province (Grant No.BS2007041).

\section{References}

[1] Jeong SH, Lee K, Chong Y, Yum JH, Lee SH, Choi HJ, Kim JM, Park KH, Han BH, Lee SW, Jeong TS,. Characterization of a new integron containing VIM-2, a metallobeta-lactamase gene cassette, in a clinical isolate of Enterobacter cloacae. J Antimicrob Chemother. 2003;51(2):397-400.

[2] Ahmed AM, Nakano H, Shimamoto T, Molecular characterization of integrons in non-typhoid Salmonella serovars isolated in Japan: description of an unusual class 2 integron. J Antimicrob Chemother. 2005, 55(3):371-4.

[3] Hall RM, Mobile gene cassettes and integrons: moving antibiotic resistance genes in gram-negative bacteria. Ciba Found Symp. 1997, 207:192-202; discussion 202-5.

[4] Hollingshead S, Vapnek D, Nucleotide sequence analysis of a gene encoding a streptomycin/spectinomycin adenyltransferase. Plasmid. 1985,13:17-30. 
[5] Clark NC, Olsvik O, Swenson JM, Spiegel CA, Tenover FC, Detection of a streptomycin/spectinomycin adenylyltransferase gene (aadA) in Enterococcus faecalis. Antimicrob. Agents Chemother. 1999, 43:157-160.

[6] National Committee for Clinical Laboratory Standards. Methods for Dilution Antimicrobial Susceptibility Tests for Bacteria that Grow Aerobically: Approved Standard. 1997. M7-A4, M7-A4. NCCLS, Villanova, PA, USA.

[7] Lévesque C, Piché L, Larose C, Roy PH, PCR mapping of integrons reveals several novel combinations of resistance genes. Antimicrob. Agents Chemother. 1995, 39, 185-191.

[8] Valverde AR, Canto'n JC, Galán JC, In117, an unusual In0-like class 1 integron containing CR 1 and blaCTX-M-2 and associated with a Tn21-like element. Antimicrob. Agents Chemother. 2005, 50:799-802.

[9] Lee K, Lim JB, Yum JH, Yong D, Chong Y, Kim JM,
Livermore DM, bla(VIM-2) cassette-containing novel integrons in metallo-beta-lactamase-producing Pseudomonas aeruginosa and Pseudomonas putida isolates disseminated in a Korean hospital. Antimicrob. Agents Chemother. 2002, 46, $1053-8$.

[10] Hall RM, Collis CM, Kim MJ, Partridge SR, Recchia GD, Stokes HW, Mobile gene cassettes and integrons in evolution. Ann N Y Acad Sci. 1999, 870: 68-80.

[11] Sun C, Su Z, Zhou C, Liu Y, Yuan H, Yin J, Xu H, Complex class 1 integron containing bla ( CTX-M-1) genes isolated from Escherichia coli: a potentially novel resistant gene-capturing tool kit.Curr Microbiol. 2012,64(3):265-70.

[12] Xu H, Su Z, Wang S, Dai X, Chen J, Kong F, Li Y, Peng S, Shao $\mathrm{Q}, \mathrm{Lu} \mathrm{L}$, Ezaki T, Four novel resistance integron gene-cassette occurrences in bacterial isolates from zhenjiang, china. Curr Microbiol. 2009, 59(2):113-7. 